\title{
The effects of autumn rotation length and cutting height on a perennial ryegrass-white clover
} sward

P. Phelan ${ }^{1,2}$, B. Keogh ${ }^{2}$, I. A. Casey ${ }^{2}$, E. Fitzgerald ${ }^{2}$, J. Humphreys ${ }^{1}$

${ }^{1}$ Teagasc Dairy Production Research Centre, Moorepark, Fermoy, Co. Cork, Ireland

${ }^{2}$ Department of Chemical and Life Sciences, Waterford Institute of Technology,, Cork road, Waterford,, Ireland

Email: paul.p.phelan@teagasc.ie

Introduction The proportion of white clover in grass swards usually declines in winter. The extent of this decline and subsequent recovery can affect white clover persistence. The objective of this experiment was to examine the effects of autumn rotation length and cutting height on herbage production and persistence of a white clover-perennial ryegrass sward.

Material and methods This experiment was conducted on a permanent grass-clover sward at Solohead Research Farm $\left(52^{\circ} 51^{\prime} \mathrm{N}, 08^{\circ} 21^{\prime} \mathrm{W}\right)$ and involved 4 rotation lengths $(21,42,56$ or 84 days $)$ and 4 cutting heights $(2.7,3.6,5.4$ or $5.9 \mathrm{~cm}$ above ground level). Treatments were imposed between July and December, 2008. Between March and June, 2009 all plots were harvested at 28-day intervals to a cutting height of $4.5 \mathrm{~cm}$. Plots $(8 \mathrm{~m} \times 2 \mathrm{~m})$ were laid out in a randomised complete block design with a factorial arrangement of treatments and 5 replications. Herbage dry matter (DM) yields, clover contents of herbage and clover stolon DM masses were measured. Results were analysed using PROC MIXED in SAS. Time (sampling date) was included as a repeat measure for stolon DM masses. All two-way and three-way interactions were examined.

Results For all results, there were no interactions between the two treatment factors; rotation length and cutting height $(\mathrm{P}>$ 0.05). The highest mean herbage and mean clover herbage DM yield was associated with the 42-day rotation and with the two lower cutting heights $(\mathrm{P}<0.001)$ (Figure 1), while lower mean grass DM yield was only associated with the 21-day rotation $(\mathrm{P}<0.001)$. Mean stolon DM mass changed typically over time and was affected by interactions between time and rotation length (Figure 2 (A)) and between time and cutting height (Figure 2 (B)). The lowest mean stolon DM mass was associated with the 21-day rotations. Lower cutting heights increased stolon masses only on the final sampling date $(\mathrm{P}<$ $0.05)$.
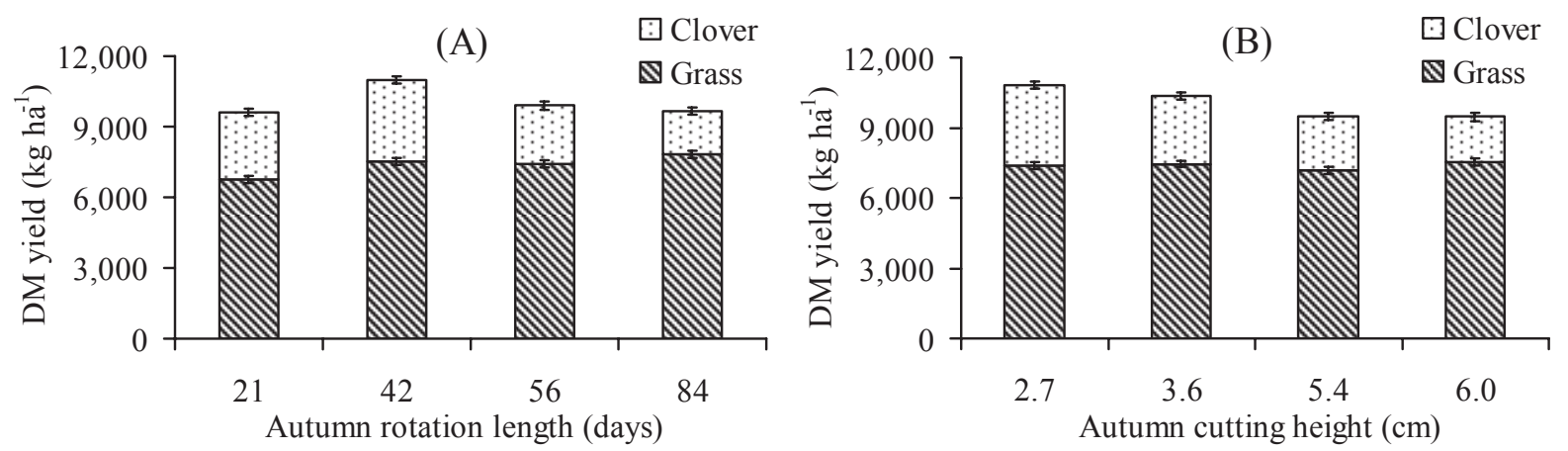

Figure 1 Mean clover and grass dry matter (DM) yield (kilogram hectare ${ }^{-1}\left(\mathrm{~kg} \mathrm{ha}^{-1}\right)$ ) produced between July 2008 and July 2009 for (A) rotation length in autumn and (B) cutting height in autumn. Error bars indicate the standard error of the mean.
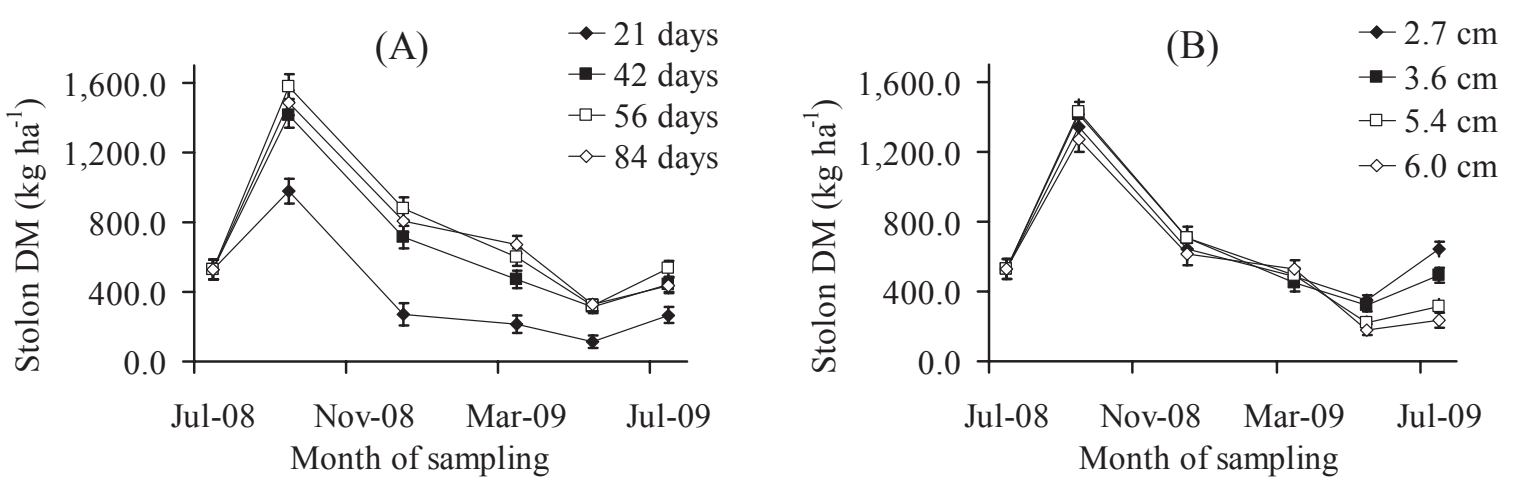

Figure 2 Changes in mean clover stolon dry matter (DM) mass (kilogram hectare ${ }^{-1}\left(\mathrm{~kg} \mathrm{ha}^{-1}\right)$ ) over time for (A) rotation length in autumn and (B) cutting height in autumn. Error bars indicate the standard error of the mean.

Conclusions A 42-day rotation combined with a low cutting height $(2.7$ to $3.6 \mathrm{~cm})$ in autumn gave the most desirable outcome in terms of annual herbage yield, clover yield and stolon mass during the following spring/summer. Short (21-day) rotations should be avoided during the autumn because of their negative impact on stolon mass.

Acknowledgements This project was funded by the Department of Agriculture and Food Research Stimulus Fund (RSF07511). 